\title{
Self assessment of Portuguese doctors dealing with HPV: portrait of screening, vaccination, counseling
}

\author{
Joana Aidos, Maria Inês Reis, Renata Veríssimo, Ana Rita Pinto, Nuno Nogueira Martins
}

\author{
Corresponding author: Joana Aidos, Obstetrics and Gynaecology Department, Centro Hospitalar \\ Tondela - Viseu, E.P.E., Av. Rei Dom Duarte, 3504-509, Viseu, Portugal.; Email - \\ joanaaidos@hotmail.com
}

Distributed under Attribution-Non Commercial - Share Alike 4.0 International (CC BY-NC-SA 4.0)

\begin{abstract}
Objectives: The aim of this study was to assess the way that doctors themselves, who often deal with human papilloma virus, embrace the subject from a personal perspective. Methods: The study design was a survey questionnaire. Authors have included 460 female gynaecologists and general practicioners (GPs) working in Portugal, whose responses were duly validated. Inclusion criteria: women aged $\leq 45$ years who agreed to take the survey, and already have had sexual intercourse. Data were collected in January 2015 using an electronic survey that ensured complete confidentiality. Results: The survey showed that most doctors accepting to take part in the survey were young doctors, of which $74.8 \%$ were GPs and $2.4 \%$ had never been screened for cervical cancer. Only $56.1 \%$ of respondents had been vaccinated against HPV. Statistical significance $(p<0.05)$ was observed between vaccination and the age, region, specialty and vaccination counseling of its patients, relatives and friends. Conclusions: Surprisingly, there are several facts concerning prevention of cervical cancer that still need to be clarified, even amongst the doctors who provide direct care to the population on the field, so that they start by adopting the recommended measures themselves, which may ultimately lead to an improvement in global health care.
\end{abstract}

Keywords: Cervical cancer, screening, vaccination, papillomaviridae.

Cervical cancer represents $6 \%$ of all gynecological malignancies. ${ }^{1}$ Cervical cancer is the fourth most frequent cancer in women with an estimated 570,000 new cases in 2018. Approximately $90 \%$ of deaths from cervical cancer occurred in low and middle income countries. ${ }^{2}$ In Portugal, it is the fourth most frequent tumor in women and is the second cause of death in this group, followed by breast cancer. ${ }^{3}$ According to the 2010 National Oncology Registry, the gross incidence rate in Portugal was $13.5 / 100,000$ and the standardized rate of $11.3 / 100,000$ women. ${ }^{3}$ In 2012, 720 new cases of cervical cancer were diagnosed. ${ }^{4}$

However, there has been a decline in their incidence. ${ }^{3}$
What may have contributed towards this decrease was probably the increasing number of women included in the screening programs, which was more significant in the year $2010^{3}$, as well as the introduction of the human papilloma (HPV) vaccine. This vaccine has been part of the National Vaccination Plan since 2008, in which the Government has offered the vaccine to all 13 year old female teenagers (and simultaneously to all the 17 year old girls during the first 3 years of the program $)^{5}$. The vaccine is also available to all women under the age of 45 who desire to buy it.

It is estimated that 300 million women worldwide are HPV carriers and $32 \%$ are infected with HPV 16 and/or $18 .{ }^{6}$

Received: $10^{\text {th }}$ February 2020. Accepted: $1^{\text {st }}$ April 2020.

Aidos J, Reis MI, Veríssimo R, Pinto AR, Martins NN. Self assessment of Portuguese doctors dealing with HPV: portrait of screening, vaccination, counseling. The New Indian Journal of OBGYN. 2020; 7(1): 41-7. 
The vaccine demonstrated efficacy, immunogenicity and safety profile in women aged 24-45 regardless of prior exposure to HPV. ${ }^{7,8}$ Vaccination programs are cost-effective when compared to routine surveillance. ${ }^{9}$ In males with age between 16 and 26, it prevents infection. However, at least for now, most of the economic evaluation studies regarding HPV vaccination in males have not yet shown results regarding prevention of cervical cancer. ${ }^{10}$

The importance of early detection of cancer precursor lesions was demonstrated in $1940^{11}$ and its efficacy is documented in multiple studies. ${ }^{12-17}$ It is the main form of secondary prevention. Countries with screening coverage greater than $50 \%$, performed every three to five years, have rates below three deaths per 100,000 women per year, and for those with coverage greater than $70 \%$, this rate is less than or equal to two deaths per 100,000 women per year. ${ }^{18}$

The authors decided to study, in the medical population responsible for screening cervical cancer in the general population in Portugal, their own adherence to the screening programs and the percentage of female doctors vaccinated against HPV. They have then compared the conduct adopted by this specific population with the recommendations of the screening and vaccination programs.

\section{Materials and methods}

A survey was carried out among female doctors from the specialties of Gynaecology and Obstetrics, as well as GPs, aged under 45 years old. The doctors who were invited to take part in the study were the ones included in the database of the Portuguese Network of Trainees in Obstetrics and Gynecology and in the social network groups of the Portuguese Association of General Medicine. The link to the survey was sent by email, reassuring full confidentiality.

Inappropriately completed surveys, women had not started their sex life and /or over the age of 46, were excluded. Data was collected during the month of January, 2015.

The authors assessed the demographic characteristics (including age, specialty, and region of the country where they work), gynecological and obstetric history, cervical cancer screening, and HPV vaccination status. They also inquired whether the physicians recommend the vaccine to their relatives, their patients and the male gender.

They performed statistical analysis using IBM SPSS software version $22.0 \AA$. The variables were summarized using absolute and relative frequencies. The Chi-square and Fisher exact tests were applied to evaluate the association between the variables, considering a statistical significance of $\mathrm{p}<0.05$.

\section{Results}

The authors obtained $460(96,8 \%)$ valid responses from a universe of 475 responses. Sociodemographic characteristics and risk factors for cervical cancer are summarized in table 1. The majority of physicians were GPs between 25 and 34

Table 1: Social and demographic data, obstetric history, and risk factors for cervical cancer.

\begin{tabular}{|c|c|c|c|}
\hline Sociodemographic data & & $\mathrm{N}$ & $\%$ \\
\hline \multirow{4}{*}{ Age (years) } & $25-29$ & 279 & $60.7 \%$ \\
\hline & $30-34$ & 121 & $26.3 \%$ \\
\hline & $35-39$ & 47 & $10.2 \%$ \\
\hline & $40-45$ & 13 & $2.8 \%$ \\
\hline \multirow{3}{*}{ Specialty } & Gynaecology and & & \\
\hline & Obstetrics & 116 & $25.2 \%$ \\
\hline & $\begin{array}{l}\text { General } \\
\text { Practicioners }\end{array}$ & 344 & $74.8 \%$ \\
\hline \multirow{4}{*}{$\begin{array}{l}\text { Region of the country in which } \\
\text { participants practice }\end{array}$} & North & 176 & $38.3 \%$ \\
\hline & Center & 137 & $29.8 \%$ \\
\hline & South & 129 & $28.0 \%$ \\
\hline & Islands & 18 & $3.9 \%$ \\
\hline \multicolumn{4}{|l|}{ Obstetrical history } \\
\hline \multirow{4}{*}{ Parity } & Nulliparous & 353 & $76.7 \%$ \\
\hline & 1 & 60 & $13.0 \%$ \\
\hline & 2 & 29 & $6.3 \%$ \\
\hline & $\geq 3$ & 18 & $3.9 \%$ \\
\hline \multirow{3}{*}{$\begin{array}{l}\text { Type of delivery }{ }^{*} \text { Question with } \\
\text { more than one answer option }\end{array}$} & Cesarean section & 62 & $57.9 \%$ \\
\hline & Eutocic delivery & 64 & $59.8 \%$ \\
\hline & $\begin{array}{l}\text { Instrumental } \\
\text { delivery }\end{array}$ & 32 & $29.9 \%$ \\
\hline \multicolumn{4}{|l|}{ Risk factors for Cervical Cancer } \\
\hline \multirow{6}{*}{ Smoking habits (Cigarettes/day) } & $<5$ & 19 & $4.1 \%$ \\
\hline & $5-10$ & 7 & $1.5 \%$ \\
\hline & $10-20$ & 11 & $2.4 \%$ \\
\hline & $>20$ & 1 & $0.2 \%$ \\
\hline & Ex-smoker & 35 & $7.6 \%$ \\
\hline & Never & 387 & $84.1 \%$ \\
\hline \multirow{2}{*}{ Immunossuppression } & No & 451 & $98.0 \%$ \\
\hline & Yes & 9 & $2.0 \%$ \\
\hline \multirow{3}{*}{ Menarche (years) } & $<12$ & 142 & $30.9 \%$ \\
\hline & $12-14$ & 289 & $62.8 \%$ \\
\hline & $>14$ & 29 & $6.3 \%$ \\
\hline \multirow{4}{*}{ Coitarche (years) } & $\leq 15$ & 18 & $3.9 \%$ \\
\hline & $16-17$ & 93 & $20.2 \%$ \\
\hline & $18-19$ & 164 & $35.7 \%$ \\
\hline & $\geq 20$ & 185 & $40.2 \%$ \\
\hline \multirow{4}{*}{ No of sexual partners } & 1 & 183 & $39.8 \%$ \\
\hline & $2-3$ & 170 & $37.0 \%$ \\
\hline & $4-5$ & 67 & $14.6 \%$ \\
\hline & $>5$ & 40 & $8.7 \%$ \\
\hline
\end{tabular}

years of age, nulliparous, non-smokers and practiced in the North and Center of the country. Results regarding cervical cancer screening, prophylactic HPV vaccination and attitudes towards vaccination are described in table 2 and 3. The majority adhered to the recommendations for the start of screening for cervical cancer and only $20 \%$ did it belatedly. However, $2.4 \%$ of them had never had a cervical cytology themselves and $7.2 \%$ had done the last one over 3 years 
The New Indian Journal of OBGYN. 2020 (July-December); 7(1)

Table 2: Cervical cancer screening

\begin{tabular}{|c|c|c|c|}
\hline \multicolumn{2}{|l|}{ Cervical cancer screening } & $\mathbf{N}$ & $\%$ \\
\hline \multirow{3}{*}{ Screening start (years) } & $<20$ & 110 & $23.9 \%$ \\
\hline & $\geq 21$ & 339 & $73.7 \%$ \\
\hline & Never & 11 & $2.4 \%$ \\
\hline \multirow{3}{*}{$\begin{array}{l}\text { Start of the screening } 3 \text { years } \\
\text { after coitarche }\end{array}$} & No, more precocious & 180 & $40.1 \%$ \\
\hline & No, later & 90 & $20.0 \%$ \\
\hline & Yes & 179 & $39.9 \%$ \\
\hline \multirow{3}{*}{ Colpocytology } & Conventional citology & 201 & $44.8 \%$ \\
\hline & Liquid base & 219 & $48.8 \%$ \\
\hline & Don't know specify & 29 & $6.5 \%$ \\
\hline \multirow{5}{*}{ Last colpocytology } & Never done & 11 & $2.4 \%$ \\
\hline & $<1$ year & 266 & $60.2 \%$ \\
\hline & $1-2$ & 113 & $24.6 \%$ \\
\hline & $2-3$ & 37 & $8.0 \%$ \\
\hline & $>3$ years & 33 & $7.2 \%$ \\
\hline \multirow{3}{*}{ Where collect colpocytology } & Health Center & 116 & $25.8 \%$ \\
\hline & Hospital & 57 & $12.7 \%$ \\
\hline & Private institution & 276 & $61.5 \%$ \\
\hline \multirow{8}{*}{$\begin{array}{l}\text { Alterations in last } \\
\text { colpocytology }\end{array}$} & Normal & 348 & $77.5 \%$ \\
\hline & Inflammation & 69 & $15.4 \%$ \\
\hline & Infection & 9 & $2.0 \%$ \\
\hline & ASCU-US & 14 & $3.1 \%$ \\
\hline & ASC-H & 1 & $0.2 \%$ \\
\hline & AGC & 1 & $0.2 \%$ \\
\hline & LSIL & 7 & $1.6 \%$ \\
\hline & HSIL & 0 & $0 \%$ \\
\hline \multirow{2}{*}{ Genital condylomatous lesions } & No & 452 & $98.3 \%$ \\
\hline & Yes & 8 & $1.7 \%$ \\
\hline \multirow{2}{*}{ Co-test } & No & 371 & $80.7 \%$ \\
\hline & Yes & 89 & $19.3 \%$ \\
\hline \multirow{6}{*}{ HPV test } & Never & 368 & $80,0 \%$ \\
\hline & $<24$ years & 8 & $1.7 \%$ \\
\hline & $\geq 25$ years & 18 & $3.9 \%$ \\
\hline & Negative & 71 & $15.4 \%$ \\
\hline & Positive - Lower grade & 8 & $1.7 \%$ \\
\hline & Positive - High grade & 5 & $1.1 \%$ \\
\hline \multirow{2}{*}{$\begin{array}{l}\text { Cervico-vulvo-vaginal } \\
\text { Appointment }\end{array}$} & No & 445 & $96.7 \%$ \\
\hline & Yes & 15 & $3.3 \%$ \\
\hline \multirow{6}{*}{ Cervico-vulvar treatment } & No & 435 & $94.6 \%$ \\
\hline & Cervical biopsy & 2 & $0.4 \%$ \\
\hline & Conization & 3 & $0.7 \%$ \\
\hline & Cryocoagulation & 9 & $2.0 \%$ \\
\hline & Diathermocoagulation & 6 & $1.3 \%$ \\
\hline & $\begin{array}{l}\mathrm{CO} 2 \text { Laser } \\
\text { Vaporization }\end{array}$ & 5 & $1.1 \%$ \\
\hline
\end{tabular}

before. In what concerns HPV testing, it had been performed in 89 cases, of which 13 were positive, with high - risk HPV detection in 4 of those.

Regarding vaccination against HPV, $56.1 \%$ of the respondents were vaccinated. The recombinant tetravalent vaccine against HPV genotypes $6,11,16$ and 18 was the preferred one, as the nine-type vaccine was not available at the time of the study. In $93.1 \%$ of cases of the vaccinated women, the main promoting agents for vaccination were medical advice and available scientific information. From the non-vaccinated sub-group, about two thirds thought the vaccine was expensive or non-effective. In their clinical
Table 3: Cervical cancer vaccination against HPV, and personal and professional attitude toward vaccination

\begin{tabular}{|c|c|c|c|}
\hline \multicolumn{2}{|c|}{ Prophylatic vaccination against HPV } & \multirow{2}{*}{$\frac{\mathbf{N}}{202}$} & \multirow{2}{*}{$\begin{array}{r}\% \\
43.9 \%\end{array}$} \\
\hline & No & & \\
\hline Vaccination & Yes & 258 & $56.1 \%$ \\
\hline \multirow{6}{*}{ Age of vaccination (years) } & Teenager & 1 & $0.4 \%$ \\
\hline & $18-25$ & 173 & $67.1 \%$ \\
\hline & $26-30$ & 72 & $27.4 \%$ \\
\hline & $31-35$ & 10 & $3.9 \%$ \\
\hline & $36-40$ & 1 & $0.4 \%$ \\
\hline & $41-45$ & 1 & $0.4 \%$ \\
\hline \multirow{2}{*}{ Type of vaccine } & Bivalent & 30 & $11.6 \%$ \\
\hline & Tetravalent & 228 & $88.4 \%$ \\
\hline \multirow{2}{*}{3 admnistrations } & No & 12 & $4.7 \%$ \\
\hline & Yes & 246 & $95.3 \%$ \\
\hline \multirow{4}{*}{ Vaccinated, the reason was } & Medical advise & 104 & $40.3 \%$ \\
\hline & Scientific information & 137 & $53.1 \%$ \\
\hline & Laboratory offer & 16 & $6.2 \%$ \\
\hline & Other advise & 1 & $0.4 \%$ \\
\hline \multirow{6}{*}{ Not vaccinated, the reason was } & Will still do & 29 & $14.4 \%$ \\
\hline & Forgetfulness & 21 & $10.4 \%$ \\
\hline & $\begin{array}{l}\text { Does not consider } \\
\text { important }\end{array}$ & 64 & $31.7 \%$ \\
\hline & Price & 49 & $24.3 \%$ \\
\hline & $\begin{array}{l}\text { Apprehension } \\
\text { price/effectiveness }\end{array}$ & 27 & $13.4 \%$ \\
\hline & Other reason & 12 & $5.9 \%$ \\
\hline \multicolumn{4}{|l|}{ Opinion related to vaccination } \\
\hline \multirow{2}{*}{$\begin{array}{l}\text { Works regularly with cervical- } \\
\text { vulvo vaginal pathology }\end{array}$} & No & 139 & $30.2 \%$ \\
\hline & Yes & 321 & $69.8 \%$ \\
\hline \multirow{5}{*}{$\begin{array}{l}\text { Advises vaccination to } \\
\text { patients }\end{array}$} & No & 30 & $6.5 \%$ \\
\hline & Discretion of the patient & 210 & $45.7 \%$ \\
\hline & Yes & 220 & $47.8 \%$ \\
\hline & Bivalent & 31 & $6.7 \%$ \\
\hline & Tetravalent & 189 & $41.1 \%$ \\
\hline \multirow{2}{*}{$\begin{array}{l}\text { Advises vaccination to } \\
\text { relatives or/and friends }\end{array}$} & No & 96 & $20.9 \%$ \\
\hline & Yes & 364 & $79.1 \%$ \\
\hline \multirow{2}{*}{$\begin{array}{l}\text { Knowledge of some boy } \\
\text { vaccinated }\end{array}$} & No & 413 & $89.8 \%$ \\
\hline & Yes & 47 & $10.2 \%$ \\
\hline \multirow{2}{*}{$\begin{array}{l}\text { Advises vaccination to } \\
\text { masculine gender }\end{array}$} & No & 229 & $49.8 \%$ \\
\hline & Yes & 231 & $50.2 \%$ \\
\hline
\end{tabular}

Table 4: Logistic regression for determination of risk factors for changes in cytology; Dependent variable: Changes in cytology; Independent variables: coitarche, number of sexual partners; immunosuppression and smoking habits.

\begin{tabular}{lllll}
\hline Parameters & OR & P & $\begin{array}{l}\text { IC 95\% } \\
\text { Inferior }\end{array}$ & $\begin{array}{c}\text { (OR) } \\
\text { Superior }\end{array}$ \\
\hline 1 sexual partner & 0.22 & $0.001^{*}$ & 0.09 & 0.53 \\
2-3 sexual partners & 0.45 & $0.049^{*}$ & 0.21 & 1.00 \\
4-5 sexual partners & 0.43 & 0.062 & 0.18 & 1.04 \\
Coitarche 16-17 & 1.20 & 0.776 & 0.34 & 4.26 \\
Coitarche 18-19 & 2.01 & 0.265 & 0.59 & 6.87 \\
Coitarche $\geq$ 20 & 1.54 & 0.504 & 0.44 & 5.40 \\
Immunocompromised & 0.57 & 0.602 & 0.07 & 4.72 \\
Smokers & 1.32 & 0.502 & 0.59 & 2.94 \\
Ex-Smokers & 1.23 & 0.613 & 0.55 & 2.72 \\
Cesarian-Section & 1.08 & 0.827 & 0.55 & 2.13 \\
\hline P valuc<0.05 & & & \\
\hline
\end{tabular}

$\mathrm{P}$ value $<0.05$ is considered significant

practice, a surprising $6.5 \%$ of doctors do not promote prophylactic vaccination to their patients. Logistic regression for determination of risk factors for changes in cytology is 
Table 5: Prophylactic vaccination against HPV according to respondents' characteristics

\begin{tabular}{|c|c|c|c|c|c|c|}
\hline \multirow{3}{*}{ Parameters } & & \multicolumn{4}{|c|}{ Prophylactic vaccination against HPV } & \multirow{3}{*}{$P$ value } \\
\hline & & \multicolumn{2}{|c|}{ No } & \multicolumn{2}{|c|}{ Yes } & \\
\hline & & $\mathbf{N}$ & $\%$ & $\mathbf{N}$ & $\%$ & \\
\hline \multirow{3}{*}{ Age in years } & $25-29$ & 107 & $38.4 \%$ & 172 & $61.6 \%$ & $0.000 *$ \\
\hline & $35-39$ & 32 & $68.1 \%$ & 15 & $31.9 \%$ & \\
\hline & $40-45$ & 10 & $76.9 \%$ & 3 & $23.1 \%$ & \\
\hline \multirow{4}{*}{$\begin{array}{l}\text { Region of the country in which } \\
\text { participant practice }\end{array}$} & North & 62 & $35.2 \%$ & 114 & $64.8 \%$ & $0.001^{*}$ \\
\hline & Center & 56 & $40.9 \%$ & 81 & $59.1 \%$ & \\
\hline & South & 73 & $56.6 \%$ & 56 & $43.4 \%$ & \\
\hline & Islands & 11 & $61.1 \%$ & 7 & $38.9 \%$ & \\
\hline \multirow[b]{2}{*}{ Specialty } & Gynaecology and Obstetrics & 41 & $35.3 \%$ & 75 & $64.7 \%$ & $0.032 *$ \\
\hline & General Practicioners & 161 & $46.8 \%$ & 183 & $53.2 \%$ & \\
\hline \multirow{2}{*}{ Alterations in colpocytology } & Normal & 172 & $47.9 \%$ & 187 & $52.1 \%$ & $0.001 *$ \\
\hline & Altered & 30 & $29.7 \%$ & 71 & $70.3 \%$ & \\
\hline \multirow{2}{*}{$\begin{array}{l}\text { Cervico-vulvo-vaginal } \\
\text { Appointment }\end{array}$} & No & 196 & $44.0 \%$ & 249 & $56.0 \%$ & 0.756 \\
\hline & Yes & 6 & $40.0 \%$ & 9 & $60.0 \%$ & \\
\hline Genital condylomatous lesions & No & 201 & $44.5 \%$ & 251 & $55.5 \%$ & 0.071 \\
\hline \multirow{2}{*}{ Co-teste (Citologia + HPV) } & No & 166 & $44.7 \%$ & 205 & $55.3 \%$ & 0.462 \\
\hline & Yes & 36 & $40.4 \%$ & 53 & $59.6 \%$ & \\
\hline \multirow{4}{*}{ Advises vaccination to patients } & No & 18 & $60.0 \%$ & 12 & $40.0 \%$ & $0.000 *$ \\
\hline & Discretion of the patient & 107 & $51.0 \%$ & 103 & $49.0 \%$ & \\
\hline & Bivalent & 19 & $61.3 \%$ & 12 & $38.7 \%$ & \\
\hline & Tetravalent & 58 & $30.7 \%$ & 131 & $69.3 \%$ & \\
\hline \multirow{2}{*}{$\begin{array}{l}\text { Advises vaccination to relatives and } \\
\text { friends }\end{array}$} & No & 74 & $77.1 \%$ & 22 & $22.9 \%$ & $0.000 *$ \\
\hline & Yes & 128 & $35.2 \%$ & 236 & $64.8 \%$ & \\
\hline
\end{tabular}

$P$ value $<0.05$ is considered significant

expressed in table 4. Analyzing the relation of the vaccine with the different aspects addressed in the survey, statistical significance $(p<0.05)$ was observed between vaccination and the age, region, specialty and vaccination counseling of its patients, relatives and friends (table 5).

As the age increased, there were fewer vaccinated doctors. Prophylactic vaccination against HPV was more frequent in the Northern region of the country. The frequency of vaccination was higher in the specialty of Gynaecology and Obstetrics. The physicians who advise the HPV vaccine to their patients, family and friends are those with the highest vaccination rates $(69.2 \%$ and $64.8 \%)$, respectively.

\section{Discussion}

There are few published studies evaluating the attitudes of health professionals regarding the prevention of cervical cancer. As far as the authors could ascertain, there is no literature published on this subject in the Portuguese medical population.

High rates of coverage for screening and vaccination programs depend largely on a cohesive health care network and the individual and collective commitment of health professionals. A well-informed population about the causes, risk factors, screening methods and disease prevention will play a proactive role in their health.
The physician is the most reliable vector of available scientific information, and his attitude towards screening and vaccination against HPV is decisive. It has been demonstrated that the recommendations and guidelines provided by the clinician represent one of the most important factors of population adherence to the recommended measures. ${ }^{19,20}$ Women who were not given a strong vaccination recommendation present four times less probability to be vaccinated. ${ }^{21}$

In the population studied, about $10 \%$ did not take part in the appropriate screening for cervical cancer, according to established guidelines. These data shows that further enhancement in the dissemination of recommendations, even within the medical profession, is still necessary. Only $19.3 \%$ of the respondents underwent HPV detection. This situation is probably due to the fact that the majority of respondents $(87 \%)$ were less than 30 years old and the detection was therefore not formally indicated, since in this age group $80 \%$ of infections are transient. ${ }^{22}$ Other reason should be the fact that HPV detection has not been used as a screening test and has been reserved for some specific cytology changes (ASCUS, LSIL, AGC).

The vaccine against HPV constitutes the major scientific and public health advance in the prevention of genital cancer. Portugal currently has the highest vaccination coverage rate in Europe, at around 94\%. The girls who 
turned 14 in 2015 presented a coverage of $91 \%$ for 2 doses and $72 \%$ for 3 doses. After the change of the recommended HPV vaccine schedule $(2$ doses in the 10 and 13 years), it is observed in 2016 that girls who have bornt in 2002 have a coverage of $86 \%$ (2nd dose) and for girls who have bornt in 2003, 2004 and 2005 the values for the coverage of 2 nd dose range from $71 \%$ to $78 \%{ }^{23}$ Compared to other countries, notably the United States of America, there is a high coverage rate most likely due to the public health system and the articulated primary health care network. Given that the population studied belongs to an age group that was not covered by the initial national vaccination plan from 2008, the number of vaccinated respondents is encouraging, but at the same time also disappoints for not being universal still. ${ }^{3}$ However, the arguments put forward by the unvaccinated show that even in the medical community, there are beliefs and myths common to the rest of the population. $13.4 \%$ expressed concern about vaccine safety. International organizations with pharmacovigilance programs such as the Food and Drug Administration, Disease Control and Prevention and European Medicines Agency have repeatedly reiterated the safety profile of the vaccine, based on numerous studies. ${ }^{24-26}$ Side effects are usually transient and have no severity (pain and injection site edema, fatigue, or fever).$^{27}$

It is estimated that a vaccination program, covering almost $100 \%$ of the target population, may have an impact on the reduction of cervical cancer-related mortality in $76 \%$ of cases. ${ }^{28}$ Although all available scientific information proves the efficacy of the vaccine, $31.7 \%$ of the medical population surveyed do not consider it important. It is important to emphasize that vaccines have no therapeutic effect, do not reduce the progression to intraepithelial lesions in women with persistent infection, and they do not favor regression of lesions or viral elimination. However, there are data supporting a potential benefit of the vaccine in women with cervical lesions, in the prevention of infection / reinfection by the vaccine types, as well as reducing the recurrence of the lesions. ${ }^{23}$

Only $10.2 \%$ of the sample studied refer to know someone of the masculine gender who had already been vaccinated and $49.8 \%$ did not recommend vaccination to this population group. These results are in agreement with the literature. Although man is the vector of infection and is at risk of developing genital warts and penile neoplasia, systematic vaccination is a controversial subject, and there is still insufficient data to support it. ${ }^{10}$
The present study certainly is limited, as it did not cover the population of doctors dealing with the prevention of cervical cancer in Portugal, but it may reflect the way involved doctors face this pathology, as well as how they use the means of prevention available, by first looking into their own health and then into how they advise the population they serve. As pointed out, the fact that all doctors of these two specialties were not contacted, as well as the number of answers obtained, may have limited the results, but these may still serve as motivation for a more global investigation of other countries' reality.

\section{Conclusion}

A majority of the female doctors that answered the survey and deal with women on the field is vaccinated against HPV and also recommends vaccination to the indicated population. Nevertheless, there is still a group of doctors advising the general population that is not vaccinated and does not promote vaccination among the population who could be vaccinated. Some of these doctors are still not undergoing a proper screening program themselves. Younger physicians seem to be more concerned about screening and vaccination, so it seems advisable to further train and inform the older physicians, in order to ultimately induce behavior modification. In that sense, the promotion of continuous medical education should remain as a pillar of the strategy to ensure advantage from the tools that are currently available for the screening and prevention of cervical cancer.

\section{Conflict of interest: None. Disclaimer: Nil.}

\section{References}

1. WHO. Globocan 2008: Cancer Incidence and Mortality Worldwide. Geneva: IARC; 2010.

2. WHO. Cervical cancer. Geneva: WHO. http:// www. who. int/cancer/ prevention/ diagnosis-screening/ cervical-cancer/en/

3. Portugal-Doenças Oncológicas em números - 2015. Programa Nacional para Doenças Oncológicas. Lisbon: Directorate-General for Health; 2019.

4. Ferlay J, Steliarova-Foucher E, Lortet-Tieulent,J, Rosso $\mathrm{S}$, Coebergh JWW, Comber H. Cancer incidence and mortality patterns in Europe: estimates for 40 countries in 2012. Eur J Cancer. 2013; 49(6): 1374-1403.

5. Castellsague X, Munoz N, Pitisuttithum P, Ferris D, Monsonego J, Ault K, et al. End-of-study safety, immunogenicity, and efficacy of quadrivalent HPV (types $6,11,16,18$ ) recombinant vaccine in adult 
women 24-45 years of age. Br J Cancer. 2011; 105(1): 28-37.

6. Einstein $\mathrm{MH}$, Baron $\mathrm{M}$, Levin $\mathrm{MJ}$, Chatterjee A, Edwards RP, Zepp F, et al. Comparison of the immunogenicity and safety of Cervarix and Gardasil human papillomavirus (HPV) cervical cancer vaccines in healthy women aged 18-45 years. Human vaccines. 2009; 5(10): 705-19.

7. Giuliano AR, Palefsky JM, Goldstone S, Moreira Jr ED, Penny ME, Aranda C, et al. Efficacy of quadrivalent HPV vaccine against HPV infection and disease in males. N Engl J Med. 2011; 364(5): 401-11.

8. Seto K, Marra F, Raymakers A, Marra CA. The cost effectiveness of human papillomavirus vaccines. Drugs. 2012; 72(5): 715-43.

9. Coleman MP, Estève J, Damiecki P, Arslan A, Renard H. Trends in cancer incidence and mortality. Lyon, France: International Agency for Research on Cancer. IARC Sci Pub. 1993; 121: 521-42.

10. Kim JJ. Weighing the benefits and costs of HPV vaccination of young men. N Engl J Med. 2011; 364(5): 393-5.

11. Papanicolaou GN, Traut HF. Cancer of the Uterus: The Vaginal Smear in Its Diagnosis. Cal West Med. 1943 Aug; 59(2): 121-2.

12. Gustafsson L, Adami HO. Cytologic screening for cancer of the uterine cervix in Sweden evaluated by identification and simulation. Br J Canc. 1990; 61(6): 903-8.

13. Lăără E, Day N, Hakama M. Trends in mortality from cervical cancer in the Nordic countries: association with organised screening programmes. Lancet. 1987; 329(8544): 1247-9.

14. Miller AB, Anderson G, Brisson J, Laidlaw J, Le Pitre $\mathrm{N}$, Malcolmson P, et al. Report of a national workshop on screening for cancer of the cervix. Can Med Assoc J. 1991; 145(10): 1301-25.

15. Parkin DM, Nguyen-Dinh X, Day NE. The impact of screening on the incidence of cervical cancer in England and Wales. Br J Obstet Gynaecol. 1985; 92(2): 150-7.

16. Arbyn M, Anttila A, Jordan J, Ronco G, Schenck U, Segnan N, et al. European guidelines for quality assurance in cervical cancer screening - Summary document. Ann Oncol. 2010; 21(3): 448-58.

17. Sobotka T. Is Lowest-Low Fertility in Europe Explained by the Postponement of Childbearing? Popul Dev Rev. 2004; 30(2): 195-220.
18. Anttila A, Pokhrel A, Kotaniemi-Talonen L, Hakama M, Malila N, Nieminen P. Cervical cancer patterns with automation-assisted and conventional cytological screening: A randomized study. Int J Cancer 2011; 128(5): 1204-12.

19. Dempsey A, Cohn L, Dalton V, Ruffin M. Patient and clinic factors associated with adolescent human papillomavirus vaccine utilization within a universitybased health system. Vaccine. 2010; 28(4): 989-95.

20. Davis K, Dickman ED, Ferris D, Dias JK. Human papillomavirus vaccine acceptability among parents of 10-15-year-old adolescents. J Low Genit Tract Dis. 2004; 8(3): 188-94.

21. Rosenthal SL, Weiss TW, Zimet GD, Ma L, Good MB, Vichnin MD. Predictors of HPV vaccine uptake among women aged 19-26: importance of a physician's recommendation. Vaccine. 2011; 29(5): 890-5.

22. Ryser MD, McGoff K, Herzog DP, Sivakoff DJ, Myers ER. Impact of coverage dependent marginal costs on optimal HPV vaccination strategies. Epidemics. 2015; 11: 32-47.

23. Consenso Nacional de Vacinas contra HPV, Secção Portuguesa de Colposcopia e Patologia do Trato Genital Inferior (SPCPTGI), Sociedade Portuguesa de Ginecologia, 2017

24. Lu B, Kumar A, Castellsagué X, Giuliano AR. Efficacy and safety of prophylactic vaccines against cervical HPV infection and diseases among women: a systematic review \& meta-analysis. BMC infectious diseases. 2011;11: 13 .

25. Agorastos T, Chatzigeorgiou K, Brotherton JM, Garland SM. Safety of human papillomavirus (HPV) vaccines: a review of the international experience so far. Vaccine. 2009; 27(52): 7270-81.

26. Macartney KK, Chiu C, Georgousakis M, Brotherton JM. Safety of human papillomavirus vaccines: a review. Drug safety. 2013; 36(6): 393-412.

27. Gonçalves AK, Cobucci RN, Rodrigues HM, Melo AGD, Giraldo PC. Safety, tolerability and side effects of human papillomavirus vaccines: a systematic quantitative review. Brazilian Journal of Infectious Diseases. 2014; 18(6): 651-9.

28. Hopkins TG, Wood N. Female human papillomavirus (HPV) vaccination: global uptake and the impact of attitudes. Vaccine. 2013; 31(13): 1673-9. 
The New Indian Journal of OBGYN. 2020 (July-December); 7(1)

Joana Aidos ${ }^{1}$, Maria Inês Reis ${ }^{2}$, Renata Veríssimo ${ }^{3}$, Ana Rita Pinto ${ }^{4}$, Nuno Nogueira Martins ${ }^{5}$
1,3,4,5 Obstetrics and Gynaecology Department, Centro Hospitalar Tondela-Viseu, E.P.E.,Viseu, Portugal;

${ }^{2}$ Maternidade Dr. Alfredo da Costa, Lisboa, Portugal. 